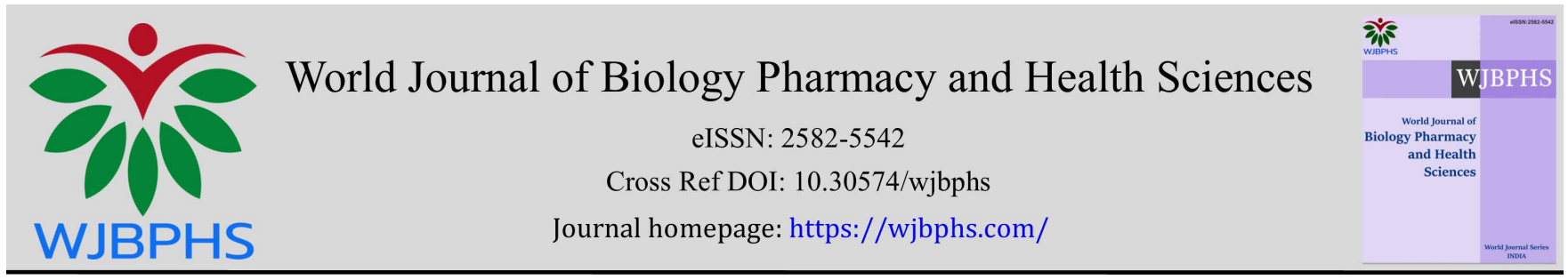

(CASE REPORT)

\title{
CT in the prize in charge of wilms 'tumor (monocentric study of 13 cases)
}

Ousmane Traore 1, 3, ${ }^{*}$, Alassane Kouma 1, 3, Fousseyni Traore 4, Issa Cisse 3, Oungoumba Diarra ${ }^{3}$, IIias Guindo ${ }^{3}$, Mamadou Dembele 3, Aboubacar Sidiki N'Diaye 3, Souleymane Sanogo 1,3 and Adama Diaman Keita 2,3

${ }^{1}$ Rradiology department, Les ETOILES" MedicalClinic (Bamako-Mali).

${ }^{2}$ Radiology department, CHU-Hôpital du POINT " G" (Bamako-Mali).

${ }^{3}$ FMOS-USTTB (Faculty of Medicine and Odontostomatology - University of Technical and Technological Science of Bamako) Bamako - Mali.

${ }^{4}$ CHU-Gabriel TOURE Hospital, Pediatric Oncology Department (Bamako-Mali).

World Journal of Biology Pharmacy and Health Sciences, 2021, 06(01), 054-060

Publication history: Received on 09 March 2021; revised on 13 April 2021; accepted on 15 April 2021

Article DOI: https://doi.org/10.30574/wjbphs.2021.6.1.0033

\begin{abstract}
Nephroblastoma or Wilms tumor is a malignant tumor that develops at the expense of embryonic kidney tissue. It is the most common kidney tumor in children (>90\%); it represents around 5\% to $14 \%$ of all childhood cancers. The aim of our work is to recall the contribution of imaging, in particular CT, in the management of this renal tumor. This is a retrospective, single-center study of 136 cases of Wilms tumors diagnosed in our clinic over a 2-year period. The mean age of the patients was 04 years with an extreme of ( 3 months -12 years) with a female prevalence (8 girls for 5 boys). Abdominal mass dominated in our study in clinical information. Histological confirmation was found in 12 cases, the only non-conforming case was lost to follow-up.
\end{abstract}

Keywords: Wilms tumor; Child; CT scan

\section{Introduction}

Nephroblastoma or Wilms tumor is a malignant tumor of the kidney that develops from tissue that mimics embryonic architecture. It can be bilateral. It is a childhood tumor, exceptional in adults [1]. It accounts for $90 \%$ of solid kidney tumors in children. As opposed to most diagnostic situations in oncology where prior histological proof is required, therapeutic management of this tumor is instituted on the basis of imaging data alone [1,2]. The role of the radiologist in the diagnosis of nephroblastoma is therefore crucial. The objective of our work is to recall the contribution of CT imaging in the management of this renal tumor in general and CT in particular.

\section{Patients and methods}

Our work is a retrospective single-center study of 13 Wilms tumors explored in the Radiology department of the "Les Etoiles " Medical Clinic and operated on in the visceral surgery department of the "G " point hospital " and in the pediatric surgery department of the 2-year-old Gabriel TOURE hospital (January 2018 - December 2020). Non-Wilms renal tumors and tumor-like infectious renal masses were excluded from this study. All patients were explored by abdominal ultrasound and abdominal computed tomography (CT). The Histological diagnosis was made on the histological study of the part of the nephrectomy in ten patients and of the echo-guided biopsy in two patients and the only remaining patient is missing.

${ }^{*}$ Corresponding author: Dr Ousmane Traore

Service de Radiologie de la Clinique Médicale ‘les Etoiles” BP: E4294 Bamako.

Copyright $(2021$ Author(s) retain the copyright of this article. This article is published under the terms of the Creative Commons Attribution Liscense 4.0. 


\section{Results}

These are 8 girls and 5 boys [Figure 2]. The average age is 3 years (range: 4 days - 12 years) [Figure 1]. The reason for CT scan was an abdominal mass (8 cases), a suspicion of nephroblastoma (3 cases), hematuria (2 cases) [Table 1]. The mass was palpable in 11 patients. On ultrasound, the renal origin of the lump was confirmed in 12 cases. On CT, microcalcifications were present in 2 cases. After injection of contrast product, the enhancement was moderate and heterogeneous in 11 cases and intense in 2 cases[Figure 3,4,5 and 6]. Retroperitoneal lymphadenopathy was present in 1 patient. Tumor renal involvement was bilateral in a 10-year-old boy.

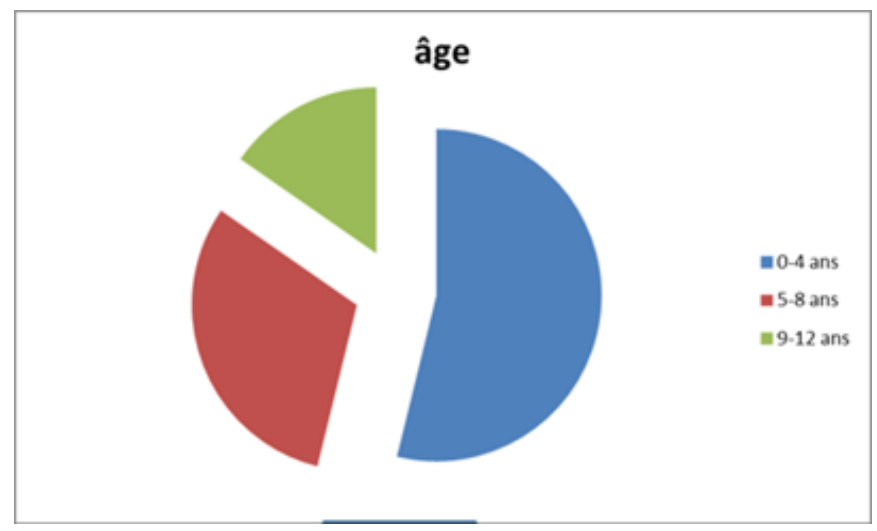

Figure 1 Distribution of patients by age

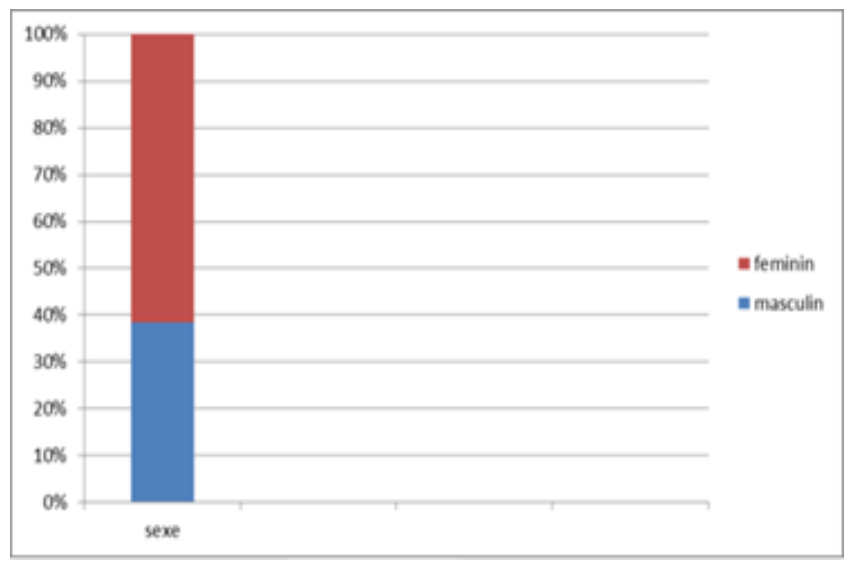

Figure 2 Distribution by sex

Table 1 Distribution of patients according to clinical information

\begin{tabular}{|c|c|}
\hline Clinical Information & Patients \\
\hline Abdominal mass & 8 \\
\hline Suspected nephroblastoma & 3 \\
\hline Hematuria & 2 \\
\hline
\end{tabular}




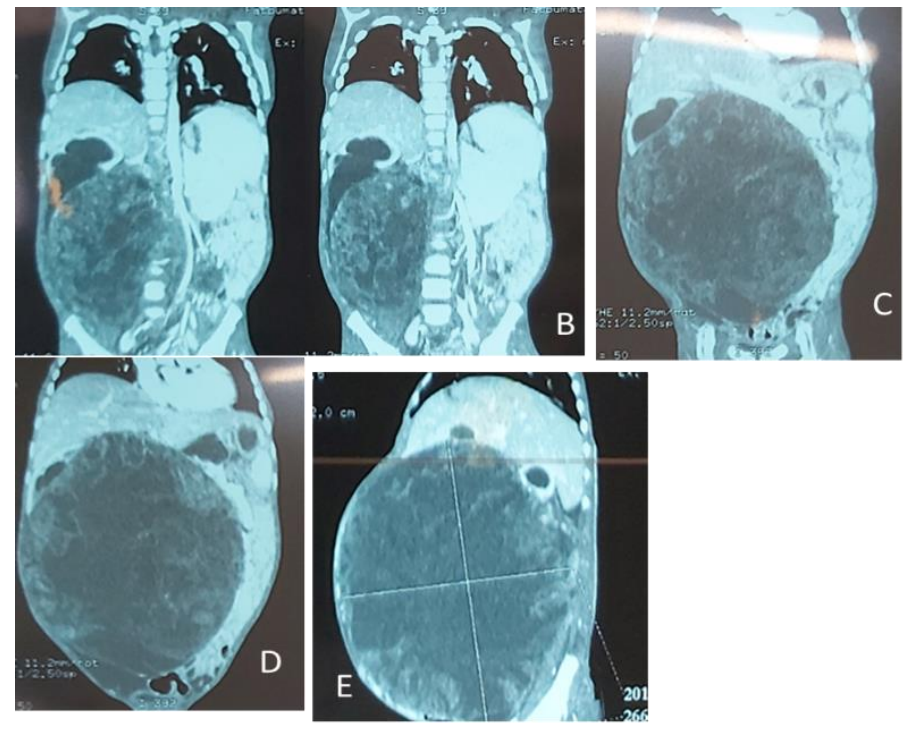

Figure 3 Abdominal CT scan; A,B,C, and D(coronal slice) E (sagittal slice) Nephroblastoma of the right kidney: 10- year -old girl with large heterogeneous mass encapsulated right retro peritoneal enhanced with the PDC site of necrosis zone infiltrating the right kidney.
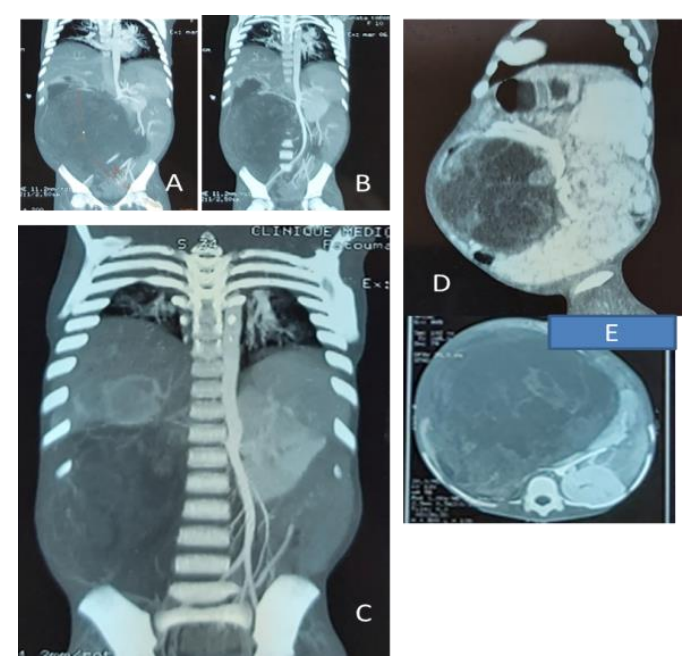

Figure 4 A, B, C, D and E showing nodular hepatic infiltration with repression of the aorta and thrombosis of the right renal vein retained patency of the aorta.

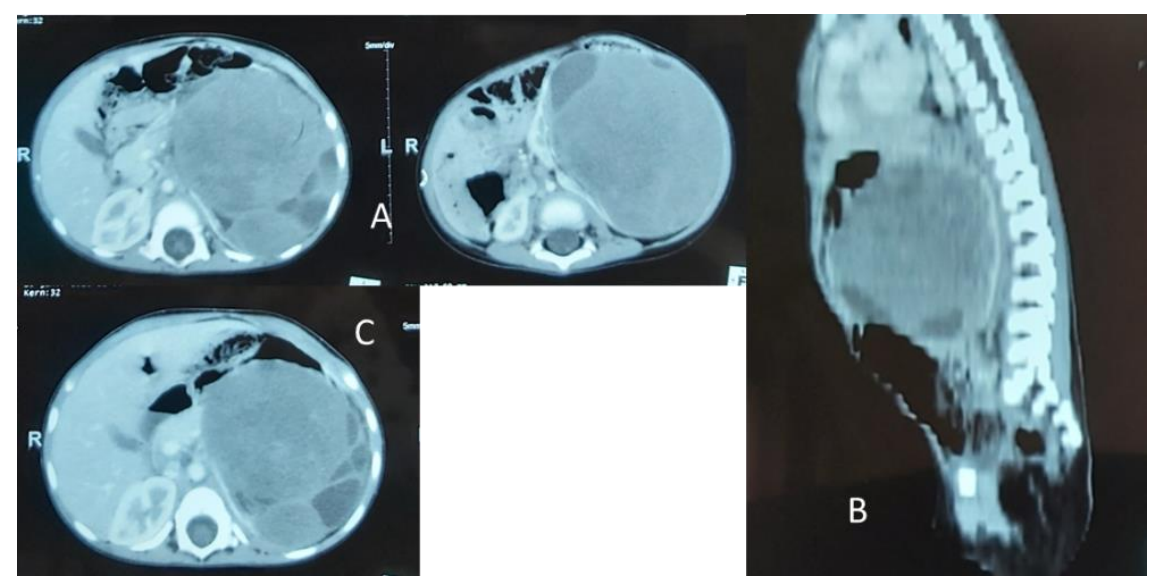

Figure 5 Nephroblastoma of the left kidney in a 9-year-old subject (Encapsulated mass enlarging the left kidney with a repressed aspect of the great vessels. 


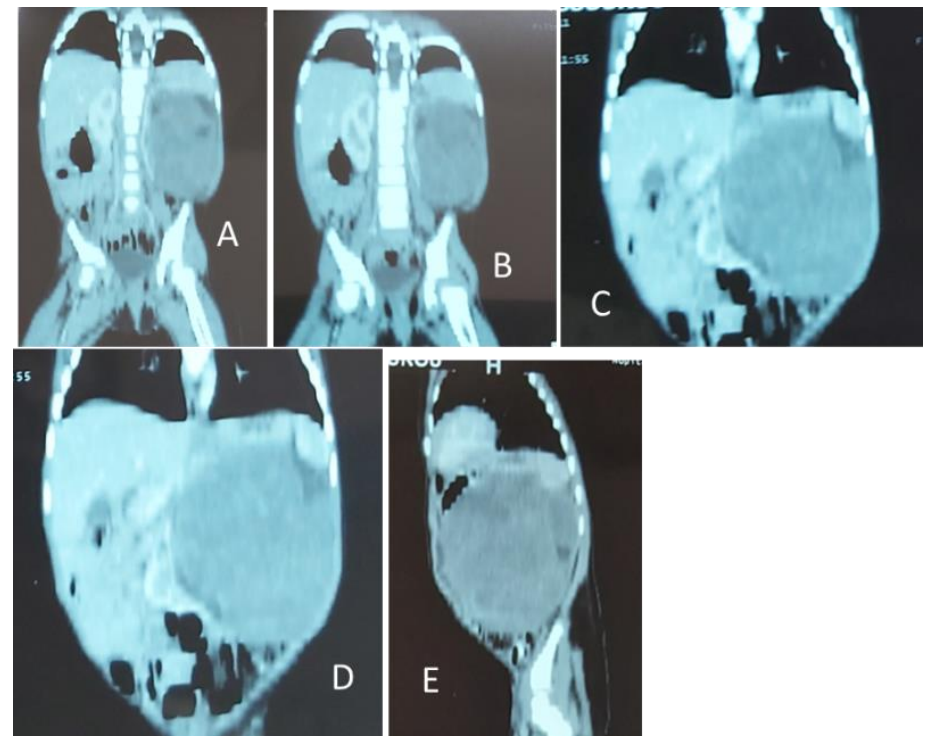

Figure 6 Nephroblastoma left kidney (abdominal CT With corona reconstruction A, B, C and D and sagittal reconstruction $\mathrm{E}$.

\section{Discussion}

Kidney tumors in children are caused mainly by nephroblastoma or Wilms tumor. The latter constitutes $90 \%$ of pediatric renal tumors, "non-Wilms" renal tumors only constitute $10 \%$ of renal masses [1,2]. It represents $8 \%$ of pediatric malignancies in Europe, its incidence is 1 / 10,000 births [2,3]. In Mali, we do not have precise statistics, but there is a marked increase in its incidence, very probably due to progress in imaging techniques and better training of doctors in medical imaging and pediatric oncology. This tumor mainly affects children, between one and five years old with an average age of four years. There is a predominance of female sex at around 58\%. With 95\% unilateral involvement. Bilateral and / or multifocal tumors are linked to the presence of embryonic nephrogenic residues (nephroblastomatosis).

\subsection{Clinical Symptomatology}

Clinically, the tumor is most often revealed by a mass syndrome [3]. It is more rarely revealed by hematuria (5\%) in our study. Rarely is it discovered in a picture of acute abdomen and / or deglobulization due to cracking or even tumor rupture. This discovery was then not found in our study. A fever is observed in $25 \%$ of cases at the time of diagnosis. Hypertension is also possible, of renovascular origin. Varicocele can be observed with venous extension [2,4].

\subsection{Anatomical Pathology $[2,5,6]$}

Macroscopically it is a tumor well limited by a pseudo-capsule, which pushes back and stretches the intra-renal cavities. Its content is most often mixed, solid with central liquid areas (due to differentiated, hemorrhagic and / or necrotic areas). Calcifications are rare (10\%) amorphous or curvilinear, only one case found in our study. An extension in the pyelocaliciel cavities is rare but possible, in particular in the infant. Histologically, this tumor is composed of three lineages in varying proportions: Blastematous, Mesenchymal, and epithelial. Very differentiated forms are observed, either on the purely solid mesenchymal side: fetal rhabdomyomatous form or on the epithelial side: partially differentiated cystic nephroblastoma $[1,6]$.

\subsection{Evolution}

The development of this tumor is very rapid, it is usually very large at the time of diagnosis, usually measuring more than 5 to $10 \mathrm{~cm}[1,7,19]$. The largest volume in our study was $112 \mathrm{~cm}$ long axis. It is a fragile tumor that can bleed and rupture in the retro peritoneum, or even in the peritoneal cavity.

\subsection{Extension: $[2,7,8]$}

Its extension is mainly vascular with a risk of thrombosis of the renal vein then of the vena cava in 5 to $10 \%$, or even intra-cardiac extension and pulmonary emboli not found in our study. Its haematogenous dissemination is mainly pulmonary (10-15\%). Retroperitoneal lymphadenopathy is rare (only one case in our study), as are extra pulmonary 
metastases (liver: $15 \%$, bone: $0.8 \%$ ). 3 to $7 \%$ have an anaplastic component, rare before two years, more frequent in black subjects; these forms are classified as "high grade" when anaplasia is diffuse because they are readily bilateral and metastatic. The stage of the tumor depends on the surgical and pathological findings:

- Stage I: The tumor is limited to the kidney and resection was complete.

- Stage II: The kidney capsule is crossed, but the excision is microscopically complete;

- Stage III: Presence of an intra-abdominal tumor residue postoperatively or an intraoperative rupture or presence of peritoneal metastases or lymphadenopathy distant from the renal pedicle

- Stage IV: Presence of hematogenous metastases; - Stage V: When the tumor is bilateral.

\subsection{Treatment: $[2,7,8,9]$}

It is currently based on preoperative tumor reduction chemotherapy which facilitates excision and reduces the local stage, followed by an enlarged total nephro-ureterectomy. On the other hand, the surgery will be partial and "economical" for bilateral tumors or on predisposing grounds. The modalities of post-operative chemotherapy depend on the stage and the histological type. Local radiotherapy is performed in case of lymph node invasion or local residue. Residual pulmonary metastases are subject to multiple excisions supplemented with the need for irradiation when they appear to be still histologically vivid. P- This is excellent for localized stages ( $96 \%$ survival at six years for stages I, stages II: $93 \%$, stages III: $83 \%)$. stages IV and V have a $65 \%$ survival at six years.

\subsection{Exploration techniques}

Imaging occupies an essential place in establishing the initial assessment and tissue characterization of kidney tumors in general and nephroblastoma in particular, thus allowing an early diagnostic approach and management. However, the differential diagnosis with other kidney tumors can be tricky, due to non-specificity of clinical and radiological signs.

\subsection{Ultrasound and Doppler ultrasound: $[1,9,10,11]$}

The radiological exploration of kidney tumors in children in general and nephroblastoma in particular is primarily based on ultrasound coupled with Doppler. It can confirm the renal origin of an abdominal mass by showing the sign of the spur. The latter results in an extension of the healthy renal parenchyma which gradually connects to the mass. Color Doppler is very useful in distinguishing healthy, well-vascularized renal parenchyma from the lesser mass that is analyzed. In addition, ultrasound makes it possible to analyze the structure of the mass (cystic, solid, or mixed), to evaluate the initial tumor volume, to carry out a locoregional extension assessment, to the renal veins and to the inferior vena cava. even at the right atrium. The exploration of the contralateral kidney is essential in the search for bilateral forms, renal malformations which would modify the therapeutic course. Use a probe suitable for the child's age: 5, 7.5, 10 Mhz. Fasting is not necessary in children.

\subsection{CT (Tomodensitometry)}

$\mathrm{CT}$ is the second-line examination for loco-regional and remote extension assessment, it allows a precise morphological study of the renal tumor syndrome to be carried out, but its major interest lies in the densitometric study before and after intravenous injection of contrast product [26]. Indeed, the healthy renal parenchyma taking the contrast is differentiated from the tumor which is slightly enhanced. If the mass is very large, the healthy renal parenchyma growing in contrast will be more easily identified (sign of the spur). We need a helical acquisition in axial sections with a passage without and with injection of iodinated PDC. The possibility of doing coronal and sagittal reconstructions.

\subsection{IVU (Intra Venous Urography)}

Has lost its interest since the advent of sectional imaging. She is looking for tumor mass syndrome. Post-CT urography has completely replaced classic intravenous urography which is no longer indicated in kidney tumors in children, particularly Wilms tumor.

\subsection{MRI (Magnetic Resonance Imaging)}

It is indicated if CT is contraindicated. Magnetic Resonance Imaging (MRI) provides better tissue characterization and accurate extension workup at the diagnostic stage and during monitoring. Given its very limited accessibility in our context, none of our patients had an MRI scan.

\subsection{Arteriography}

Arteriography is currently abandoned and is no longer used for diagnosis 


\subsection{Positive diagnosis $[1,2,12,13]$}

Cross-sectional imaging makes it possible to make a positive diagnosis of nephroblastoma by appreciating its structure, vascularization and volume. She attributed the mass to the kidney using the sign of the spur well individualized on CT and ultrasound. It also makes it possible to specify its headquarters and its reports.

\subsection{Extension assessment}

The aim of imaging is to search for thrombosis of the renal vein then for IVC (5 to 10\%) in the form of an echogenic material on ultrasound, filling the vascular lumen, which may have a vascular flow in the color doppler with the same characteristics as the initial tumor [20,24,25]. CT is more sensitive by showing dense material and no vascular enhancement after injection of iodinated PDC. Imaging makes it possible to appreciate the intracardiac extension and to look for pulmonary emboli in the form of nodules or well individualized pulmonary masses on the parenchymal windows. Hematogenous dissemination is mainly pulmonary (10-15\%). Retroperitoneal ADP (only one case in our study), extra-pulmonary metastases are rare and not found in our study. CT better assesses the extent of the renal tumor process $[13,14.15,18,19]$

\subsection{Monitoring}

It is based on the chest x-ray and on the abdomino-pelvic ultrasound looking for metastatic or local, retro and / or intraperitoneal recurrence. [2, 3,16,17] The pace of the exams is formal. The risk of contralateral metachronous recurrence is estimated at $1.5 \%$ in the event of a unilateral tumor, children aged less than 12 months at diagnosis and those with perilobarnephrogenic residues being the most at risk [20,21, 22, 23].

\section{Conclusion}

Nephroblastoma is the most common tumor in children. Its prognosis is favorable if the diagnosis is early. The different imaging methods have an essential contribution in the diagnostic approach of the tumor, the establishment of the extension assessment, and the post-therapeutic monitoring hence the interest of cross-sectional imagery. Most frequently, monitoring is performed by ultrasound.

\section{Compliance with ethical standards}

\section{Acknowledgments}

My thanks to all other authors and all those who participated from far or near to the development of this article.

\section{Disclosure of conflict of interest}

No conflict of interest.

\section{Statement of informed consent}

Informed consent was obtained from all individual participants included in the study.

\section{References}

[1] Ao Atteby, Couitchéré L, Atimere Y Et Coll. Le Néphroblastome à Abidjan : Aspects épidémiologiques, Cliniques et évolutifs Rev int sc méd -RISM. 2016; 18(1): 47-50.

[2] Zertouni M et coll. Apport de l'imagerie dans le diagnostic du néphroblastome chez l'enfant. Enseignement post universitaire JFR, Paris. 2009.

[3] Salam S et Coll. Tumeurs renales non Wilms Chez l'enfant (Etude monocentrique de 11 Cas).

[4] Avni FE, Robert Y. Imagerie du fœetus. Syllabus JFR, Paris. 1999.

[5] Hassan M, Legrand I, Garel C, Hertz-Pannier L, Tachet F. Imagerie des maladies kystiques du rein de l'enfant. Enseignement post universitaire JFR. Paris. 1991.

[6] Koff SA. Estimating bladder capacity in children. Urology. 1983; 21:248. 
[7] Hiraoka M, Tsukahara H, Tsuchida S et al. Ultrasonographic evaluation of bladder volume in children. Pediatr Nephrol. 1993;7:533-5.

[8] Hiraoka M, Chikahide H, Tsuchida S et al. Ultrasonographic evaluation of bladder volume in children. Pediatr Nephrol. 1995;9:351-3.

[9] Bis KG, Slovis TL. Accuracy of ultrasonic bladder volume measurement in children. Pediatr Radiol. 1990;20:45760.

[10] Ahmed HU, Arya M, Levitt G, Duffy PG, Mushtaq I, Sebire NJ. Primary malignant non Wilms' renal tumours in children. Lancet Oncol. 2007; 8: 730-7.

[11] Iniati D, Gay AN, Parks KV, Naik-Mathuria BJ, Hicks J, Nuchtern JG, Cass DL, Olutoye 00. Imaging accuracy and incidence of Wilms' and non-Wilms' renal tumors in children. J Pediatr Surg. 2008; 43: 1301-7.

[12] Aloui-Kasbi N, Felah S, Bellagha I, Barsaoui S, Hammou A. Imagerie des tumeurs rénales chez l'enfant. J Pediatr Puériculture. 2004; 17: 34-40.

[13] Argani P, Perlman EJ, Breslow NE, Browning NG, Green DM, D'Angio GJ, Beckwith JB. Clear cell sarcoma of the kidney. A review of 351 cases from the national Wilms tumor study group pathology center. Am J Surg Pathol. 2000; 24: 4-18.

[14] Devred P, Gorincour G, Bourlière B, Petit P, Lambot K, Coze C, Faure F. Tumeurs des reins et des voies excrétrices chez l'enfant. EMC, Radiologie et Imagerie Médicale. 2004; 34-117-A-20.

[15] Glick RD, Hicks MJ, Nuchtern JG, Wesson DE, Olutoye 00, Cass DL. Renal tumors in infants less than 6 months of age. J Pediatr Surg. 2004; 39: 522-5.

[16] Portugal R, Barroca H. Clear cell sarcoma, cellular mesoblastic nephroma and metanephric adenoma : cytological features and differential diagnosis with Wilms tumour. Cytopathology. 2008; 19: 80-5.

[17] Vujanic GM, Sandstedt B, Harms D, Kelsey A, Leushner I, de Kraker J ; SIOP. Nephroblastoma Scientific Comitee. Revised International Society of Paediatric Oncology (SIOP) working classification of renal tumors of childhood. Med Pediat Oncol. 2002; 38: 79-82.

[18] Shet T, Viswanathan S. The cytological diagnosis of paediatric renal tumours. J Clin Pathol 2009; 62: 961-9.

[19] Andon A, Vassal G et Coll. Le Néphroblastome ou Tumeur de Wilms Institut Gustave-Roussy, mai 2003 ;1-12.

[20] Yassine E . Néphroblastome sur néphroblastomatose ; Universite Mohammed V-Souissi Faculté de Médecine et de Pharmacie - Rabat thèse de médecine 2014, $\mathrm{N}^{\circ} 93$

[21] Bayoumeu F, Castel A, Verniolle M, Etcheverry J, Guyonnet M. Néphroblastome Nephroblastoma, Wilms tumor ; Prise en charge des maladies rares en anesthésie et analgésie obstétricale 2015 Elsevier Masson. 1-2

[22] Nankomba FS. Le Néphroblastome Métastatique à l'unité d'oncologie pédiatrique du Chu Gabriel Toure: Aspect clinique, therapeutique, radiologique et évolutif, Université de Bamako Thèse.2012.

[23] Founoun R. Le néphroblastome : Aspects chirurgicaux au sein du service de chirurgie infantile de CHU Mohamed VI, thèse de médecine $2017 \mathrm{~N}^{\circ} 166$.

[24] Jouini R., Maazoun K., Chelly S., Mekki M., Belghith M., Nouri A. Néphroblastomatose et néphroblastome : à propos de 2 cas ; Prog Urol. 2003; 13: 273-276.

[25] Schleiermacher, G., Brisse, H. Le néphroblastome. Oncologie. 2006; 8: 555-562.

[26] M Diezi S. Tercier. Tumeurs rénales de l'enfant Rev Med Suisse.2007; 3: 24-55. 